\title{
Carne barroca: voluptuosidad, sumisión, sublimación
}

\author{
Baroque flesh: voluptuousness, submission, sublimation
}

FRANCISCO JOSÉ MARTÍNEZ

\begin{abstract}
Resumen: Este trabajo presenta tres aspectos del cuerpo en el Barroco: el cuerpo religioso sufriente y triunfante, el cuerpo político sometido y supliciado y el cuerpo amoroso acariciado y adorado. Se trata de mostrar la ambigüedad radical del Barroco que oscila entre el apego a la vida y el culto de la muerte acabando en una tristeza resignada que sin embargo no puede dejar de mostrar cierta nostalgia respecto al sueño renacentista de afirmación de la vida, la libertad y el amor.

Palabras clave: Cuerpo, Barroco, voluptuosidad, sumisión, sublimación.
\end{abstract}

\begin{abstract}
This paper presents three aspects of the body in the Baroque: the suffering and triumphant religious body, the political body as victim under torture, and loving body cherished and adored. This is to show the radical ambiguity of Baroque ranging from attachment to life and death cult, and ending in a resigned sadness that nevertheless shows some nostalgia about the Renaissance dream of affirmation of life, freedom and love.
\end{abstract}

Keywords: Body, Baroque, voluptuousness, submission, sublimation.

\section{Introducción}

En el barroco el cuerpo, entendido como carne, es decir, ocasión de pecado, se muestra desde el punto de vista religioso como cuerpo sufriente y cuerpo triunfante, desde el punto de vista político, como cuerpo sometido y supliciado, y también como cuerpo amoroso, alabado y adorado como fuente de placeres. La carne no es solo el cuerpo sino más bien un conjunto de estructuras vitales y sociales que distraen al individuo de su principal fin: la salvación. En ese sentido carne y mundo están muy relacionados como enemigos del alma, junto con el diablo. Se puede matizar que mientras que la carne se refiere especialmente a los placeres sensuales, corpóreos y más individuales, el mundo es más una construcción social que fascina por la gloria y el poder que promete.

Las principales fuentes a las que se puede acudir para presentar al cuerpo barroco en sus diversas y plurales manifestaciones son la pintura y escultura para el cuerpo religioso; las crónicas y los tratados para el cuerpo político, la poesía para el cuerpo amado. En el barroco

Fecha de recepción: 04/06/2016. Fecha de aceptación: 17/07/2016.

* Catedrático de Metafísica de la UNED, fjmarmar@fsof.uned.es. Principales líneas de investigación: Espinosa y el Barroco y la Filosofía francesa contemporánea. Entre sus últimos escritos se encuentran: Próspero en el laberinto. Las dos caras del Barroco, Dykinson, Madrid, 2014, 280 pp. Pensar hoy: una ontología del presente, Amargord, Madrid, 2015, 335 pp. 
el cuerpo se muestra como un espacio privilegiado para representar el dolor y el goce, el triunfo de la muerte y la resistencia ardua de la vida, la victoria del poder y el placer, a pesar de su fugacidad, como el último recurso contra la muerte.

\section{Cuerpo sufriente}

Desde el punto de vista religioso el cuerpo se presenta como "el espacio y a la vez el tema de la experiencia religiosa" salvación, como el obstáculo a salvar y a la vez el medio para conseguir dicha salvación a través de la identificación con el sufrimiento de Cristo, basándose en la esperanza de que si morimos con Cristo, resucitaremos también con él. La tradición cristiana identificaba a la mujer con el cuerpo y la carne y al hombre con el espíritu y la razón y por ello la hacía más propensa a identificarse con Cristo en tanto que Dios hecho carne. Por ello la mayor parte de los fenómenos místicos, así como los estigmas y demás transformaciones del cuerpo obtenidos mediante el ascesis, se dan en mujeres, especialmente religiosas ${ }^{2}$.

El cuerpo se nos muestra en la pintura y escultura barroca como retorcido por el dolor, como cuerpo sufriente cuyo fin último es la muerte. El cuerpo se presenta como una ocasión para el dolor, como el recuerdo constante de que la tierra es un valle de lágrimas y de que nuestra parte animal debe ser reprimida y controlada sin permitirle ninguna exaltación gozosa. Sólo el tormento puede conducir al éxtasis y a la salvación. La representación barroca por excelencia del cuerpo es la que lo muestra muerto y apolillado. El memento mori, recuerda que has de morir, es uno de los fines fundamentales de la imagen barroca, que no ahorra patetismo para mostrar como los bienes del mundo son fugaces y que la sepultura es nuestro destino. En el programa iconográfico que Valdés Leal realizó en el Hospital de la Caridad de Sevilla para su fundador. Miguel de Mañara este mensaje es evidente. En el cuadro titulado 'In ictu oculi', la Muerte representada como un esqueleto que lleva un ataúd y una guadaña con una mano, con la otra apaga la luz que simboliza la vida , mientras que a sus pies se muestran en revuelto montón ,los símbolos del poder, la gloria , la riqueza y la sabiduría. En la obra titulada 'Finis Gloriae Mundi', se presenta en primer plano dos ataúdes con los cuerpos de un caballero recién muerto y el de un obispo convertido ya en esqueleto, mientras que arriba una mano celeste sujeta una balanza en la que un platillo contiene los símbolos de los pecados y otro contiene los símbolos de las virtudes, simbolizando la elección que el hombre debe efectuar entre el camino de la salvación y el de la condenación.

El cuerpo sufriente es el espacio en el que el cristiano tiene que alcanzar la santidad mediante la ascesis, mediante la mortificación ${ }^{3}$. El cuerpo sufriente es un cuerpo enfermo,

1 Cf. Gélis J., "El cuerpo, la Iglesia y lo sagrado" en Corbin A., Courtine J.J. y Vigarello G., Historia del cuerpo, vol. I, Taurus, Madrid, 2005, p. 28. A este artículo fundamental nos referiremos varias veces en lo que sigue.

2 Cf. Walker, C., "El cuerpo femenino y la práctica religiosa en la Baja Edad Media", en Feher M., Naddaff R., y Tazi, N., Fragmentos para una historia del cuerpo humano. Parte primera, Taurus, Madrid, 1990, p. 179.

3 Cf. Borja, J., "Cuerpos barrocos y vidas ejemplares: la teatralidad de la autobiografía", Fronteras de la Historia $\mathrm{n}^{\circ}$ 7, ICANH, 2002, pp. 99-115. También se puede consultar sobre el mismo tema, Aranguren, J. P., "Subjetividad y sujeción del cuerpo barroco: lo herético, lo erótico y lo ejemplar en la escritura de experiencias de vida espiritual de la monja venerable Jerónima Nava y Saavedra”, Prohal monográfico, Revista del Programa de Historia de América Latina. Vol. I. Primera Sección: Vitral Monográfico, Nro. 1. 
un cuerpo torturado mediante prácticas penitenciales muy severas: oración, ayuno, cilicios. Es un campo de batalla donde se enfrentan los vicios y las virtudes donde el alma ayudada por la fe tiene que triunfar sobre la naturaleza. El modelo que el cristianismo barroco tiene del cuerpo es el del Cristo torturado y muerto en la cruz y los cristianos, y especialmente los eclesiásticos, siguiendo en esto a San Francisco, tienen que sentir en su propio cuerpo los dolores que sufrió el redentor. El cuerpo se somete a una vigilancia constante para evitar la caída en el pecado lo que conlleva el desarrollo de una percepción muy sensible del propio cuerpo y el despliegue de una auto-reflexividad que permite la captación de la propia culpa. No se trata tanto de una renuncia al cuerpo como de su utilización, a través de la purificación que supone el dolor, como medio para conseguir lo sobrenatural.

Los místicos en su esfuerzo por identificarse con Cristo desarrollan una ascesis que reproduce los sufrimientos del Redentor. Dadas las dificultades que en esta época había para lograr el martirio, los católicos, especialmente los monjes y monjas, desarrollan una especie de martirio en diferido que es una vida de sufrimiento y dolor como imitatio Christi. Se trata de domar al cuerpo para espiritualizarlo, negar la naturaleza para conseguir lo sobrenatural, a través de la renuncia de sí, de la búsqueda de la noche de los sentidos, del sacrificio permanente, de la anticipación de la muerte, como nos recuerda Teresa de Jesús. Para ello se provoca o se incrementa la enfermedad a través de ayunos y mortificaciones con la esperanza de recibir en el propio cuerpo las llagas de Cristo, como prueba de santidad, como signo de la elección divina. En todo este proceso juega un papel esencial la imaginación que reconstruye la pasión de Cristo, recreando los espacios y las acciones de la misma, como ya enseñaba en sus Ejercicios Espirituales Ignacio de Loyola. La mística coincide con el amor cortés en la idea del dolor y el sufrimiento ligado a la no consumación del deseo y también, quizás, en la inasequibilidad última de su objetivo y su rechazo común de la sensualidad.

De todas formas la muerte no es la última palabra del cristianismo e incluso los cuerpos muertos, las reliquias, tienen un poder vivificante y en esta época se desarrolla un auténtico furor por conseguir reliquias de santos que sirven de legitimación política y de cohesión social y además son centros de atracción de peregrinos y por lo tanto fuente de riqueza y poder. Las disputas por conseguir colecciones de reliquias son constantes en la época y los monarcas se esfuerzan por reunirlas en gran número. En Wittenberg, Sajonia, se llegaron a reunir 17.000 y en el Escorial se conservan más de 7.000. La reliquia conecta el presente con el pasado estableciendo una continuidad espiritual que ayuda a la cohesión social y el prestigio político de los que las poseen y custodian ${ }^{4}$. La necesidad de multiplicación de reliquias obligaba al troceamiento de los cuerpos, y así la reliquia es generalmente un fragmento que, sin embargo, mantiene el poder salvífico del todo, mediante un proceso metonímico.

Instituto Ravignani, Facultad de Filosofía y Letras, Universidad de Buenos Aires. Buenos Aires, 2008, pp. 1-32. Torres, R. D., "Aproximaciones a la metafísica del cuerpo barroco colonial. Siglos XVII- XVIII", Tiempo e Historia: Revista de Estudiantes $\mathrm{n}^{\circ} 1$, 2012, pp. 25-60.

4 Cf. Gélis, J., op. cit. p. 91. 


\section{Cuerpo triunfante}

Pero por otro lado se muestra un cuerpo resplandeciente, triunfante, liberado de la muerte y del sufrimiento y que avanza, liberado, hacia Dios. Dicho cuerpo triunfante remite al cuerpo anterior al pecado, un cuerpo armonioso, inocente, libre de toda concupiscencia. El cuerpo triunfante se muestra brillante como un cuerpo luminoso. Esta representación de los cuerpos nimbados de luz, resplandecientes, transfigurados, expresa la supervivencia en el Barroco de la metafísica y la teología de la luz presentes en la Patrística y la Escolástica medieval y que tuvo en Bernardo de Claraval y en San Buenaventura sus principales exponentes, en Dionisio Aeropagita su iniciador y en Marsilio Ficino su filósofo.Esta teología visual y luminosa se expandió a través de la tradición oral de la mística franciscana en la que resonaba el agustinismo platonizante de los teólogos más renombrados de la orden. La luz en esta tradición mística presenta dos manifestaciones: la lumen divina y la lux humana, mero reflejo y degeneración de la primera. Se ha podido identificar el cuerpo glorioso con el cuerpo vestido de luz, e incluso afirmar que "la iluminación es el signo sensible de una comunicación de la vida divina". La luz ocupa y hace reverberar los cuerpos de los angelotes y de los santos en el cielo, es una luz que baja a la tierra y que es recogida y multiplicada gracias a espejos que sujetan los ángeles niños.

Tras el paréntesis de la muerte y la putrefacción el cristiano cree en la resurrección de la carne, un proceso que a partir de los esqueletos revitaliza el cuerpo en su plenitud ya que los cuerpos de los resucitados tendrán la edad de Cristo a su muerte, serán cuerpos gloriosos, bellos, con la armonía inicial de la creación perdida por el pecado ${ }^{5}$.

\section{Cuerpo sometido}

Desde el punto de vista político el cuerpo es central, ya sea el cuerpo del rey, base del poder y fundamento de la soberanía, como el cuerpo de los súbditos, cuerpos sometidos al poder absoluto del monarca. El cuerpo del rey en esta época es doble: por su lado su cuerpo físico, mortal, y luego su cuerpo político, inmortal, base de su 'cadáver angélico' que le hace ser, como los ángeles, inmutable en el tiempo. Los dos cuerpos del Rey, sin embargo, forman una unidad indivisible y se contienen uno en el otro, aunque el cuerpo político es más amplio que el cuerpo natural. El cuerpo natural está compuesto de miembros como el de cualquier hombre, mientras que los miembros del cuerpo político son los súbditos , mientras que el rey es la cabeza de este cuerpo místico. Que se pueda hablar de cuerpo místico y de cuerpo político de una manera indistinta trasluce el trasfondo teológico de esta teoría que llegó a constituir una 'Cristología real' con la reproducción de las discusiones que en los primeros siglos dela Iglesia tuvieron lugar en torno a la doble naturaleza de la segunda persona de la santísima trinidad . La dualidad del rey, su carácter de persona geminada, no se da solo entre su cuerpo físico y su cuerpo político sino también entre su persona humana y el carácter casi divino que adquiere por su consagración y unción que lo transforma en un Cristo, es decir en un Dios-hombre, dotado de un cuerpo natural y de un cuerpo de gracia que representa en la tierra al propio Dios con sus dos naturalezas. El

5 Cf. Gélis, J., op. cit. p. 83. 
emperador se muestra como un christomimetes, como el actor que representa y personifica a Cristo. Cuando muere el cuerpo natural del rey su cuerpo político no muere sino que se traslada a otro cuerpo natural. Mientras que el cuerpo natural del rey requiere larga vida, su cuerpo político exige perennidad, sempiternidad, dicho carácter sempiterno del cuerpo político del rey se simboliza con el halo que desde los emperadores de Bizancio rodea la cabeza de los reyes medievales. En las luchas entre el rey y el Parlamento durante la revolución inglesa, el parlamento adoptó la figura política del rey frente a la figura natural del mismo, manteniendo la autoridad regia aún contra la propia persona física del monarca . Esta dualidad del cuerpo regio se ve plásticamente en algunas de la sepulturas de reyes franceses de la basílica de Saint Denis estudiadas por Panofsky, ${ }^{6}$ sepulturas con dos niveles en las que arriba está el cuerpo político, imperecedero, y abajo el cuerpo mortal, corruptible. El cuerpo del rey como sede física del poder es el espacio en que se articulan una retórica de la imagen, una antropología de lo imaginario y una hermenéutica de lo simbólico ${ }^{7}$. El cuerpo del rey en majestad es la imagen del cuerpo de Cristo en la cruz. El cuerpo místico del rey es la imagen invertida del aspecto mortal de Cristo. El poder del rey se concreta en los hombres de armas, es decir en la fuerza, en la capacidad de dar la muerte, hasta el punto que se puede decir que 'la muerte es la máscara del rey'. Vemos aquí que en la monarquía absoluta, como muy bien supo ver Foucault, el poder del rey es fundamentalmente el de dar la muerte, actuando sobre los cuerpos de sus súbditos. La encarnación del Dios hecho carne ,diferencia infinitamente infinita, muestra en la figurabilidad ambigua del cuerpo del poder el secreto de la esfera política, el hecho de que el rey es un retrato, una figura, en la que solo los avisados distinguirán en el rey que ostenta la majestad el Cristo moribundo en la cruz. El cuerpo de Cristo crucificado es el secreto del poder del rey porque descubre tras su cuerpo político, su cuerpo físico, miserable, pero también abre la posibilidad de una transformación mediante la diferencia infinita hacia el Reino (celestial).

El Barroco es la época de las monarquías absolutas, donde los cuerpos de los súbditos están a disposición de los poderosos. El epítome de esta dominación se puede ver en el relato del suplicio de Damiens el regicida que Foucault recuerda en el inicio de Vigilar y castigar ${ }^{8}$. En la época de la soberanía el cuerpo del delincuente era el blanco principal de la represión penal y su suplicio se ofrecía como espectáculo en tanto que 'arte de las sensaciones insoportables', como modo de producir un dolor infinito. El derecho penal se considera como el derecho de dar muerte de forma atroz. El poder a través del suplicio marca al delincuente y lo hace infame y de esta manera se manifiesta de forma sensible. El delito se interpreta como un desafío al rey, y dado que éste es el representante de Dios, a Dios mismo. Por ello el suplicio es un procedimiento de restaurar la soberanía, dañada por el delito. Es la forma de exhibir la victoria del soberano todopoderoso sobre los cuerpos de sus súbditos reducidos a la impotencia. Es a la vez un 'ceremonial de triunfo' y una 'escena de afrontamiento'. El verdugo aplica la ley desplegando la fuerza, aplicando una violencia que pretende contrarrestar la violencia del crimen. El suplicio es 'revelador de la verdad' y un 'operador del

6 Cf. Panofsky E., La sculture funéraire. De l'ancienne Egypte à Bernini, Flammarion, París, 1992.

7 Cf. Marin L., "El cuerpo de poder y la encarnación en Port-Royal y Pascal o de la 'figurabilidad' del absoluto político" en Feher M., Naddaff R., y Tazi, N., Fragmentos para una historia del cuerpo humano. Parte tercera, Taurus, Madrid, 1992, pp. 424, 443, 444, 446.

8 Cf. Foucault, M., Surveiller et punir. Naissance de la prison, Gallimard, París, 1975, pp. 9-11. 
poder': "hace del cuerpo del condenado el lugar de aplicación de la venganza del soberano, el punto de anclaje de la manifestación del poder, la ocasión de afirmar la disimetría de las fuerzas". El suplicio es la explosión de la verdad y del poder; es el ritual de la investigación y la ceremonia del triunfo del soberano, ambas aplicadas sobre el cuerpo supliciado. El suplicio es un 'operador político' mediante el cual el soberano, último objetivo de cualquier crimen, se defiende de la afrenta y la castiga en el cuerpo de los culpables. El paso a la sociedad disciplinaria supondrá un cambio en los modos de castigar pasando "de un arte de las sensaciones insoportables a una economía de los derechos suspendidos", lo que supone el paso de una pena fundamentalmente corporal a una pena en cierto sentido 'espiritual', el objetivo del poder no será ya los cuerpos de los delincuentes sino su alma, su aspecto político y jurídico, lo que supone una 'penalidad de lo incorporal', al menos de forma tendencial ya que los aspectos corporales nunca se eliminan del todo de la pena.

En esta época el cuerpo no es algo a cuidar, a proteger y a encauzar sino algo a someter y controlar; estamos en el régimen de soberanía, como poder de dar la muerte, y todavía no en un régimen disciplinar ejercido sobre la vida, tanto en su aspecto individual, corporal, como en su aspecto colectivo en tanto que población.

\section{Cuerpo amado}

Tú persigues a quien volando huye

Mientras yo como un niño lloriqueo.

Mas si capturas a quien buscas vuelve,

Sé mi madre, bésame y arrúllame.

Y rogaré que colmes tu deseo

Si luego acudes a calmar mi llanto.

(Shakespeare, Soneto 143)

Mi mal difiere de todos los males; gozo con él, mi mal es lo que quiero, y mi dolor es mi salud. No sé por qué me quejo puesto que mi mal viene de mi voluntad; es mi querer el que se convierte en mi mal; pero tanto contento me produce este querer que sufro con agrado, y tanta alegría mi dolor que estoy enfermo con delicia.

Chrétien de Troyes.

En el Barroco se mantiene una idea ambigua de la mujer que ya desde la Edad Media se contemplaba como culpable pero no impura, como celestial y monstruosa a la vez, como transgresora y salvadora y carnal ante todo ${ }^{10}$. En esta época de retroceso medievalizante la

9 Cf. Foucault M., op. cit. p. 16.

10 Cf. Writh, J., "La imagen de la mujer entre teología, literatura e iconografía" en Hay más en ti. Imágenes de la mujer en la Edad Media (siglos XIII-XV), Catálogo de la Exposición que tuvo lugar en 2011 en el Museo de Bellas Artes de Bilbao, Museo Bellas Artes Bilbao, Bilbao, 2011, pp. 35-43. 
exaltación del amor humano renacentista se ve templada por el contexto contrarreformista que vuelve a contemplar dicho amor como una etapa hacia el amor divino o como una locura peligrosa e incontrolable que lleva a la perdición. La conciencia de la finitud y de la futilidad de la belleza se ve, sin embargo asaltada por la nostalgia de que el amor acabe triunfando sobre la muerte: "serán ceniza, más tendrá sentido/ polvo serán, mas polvo enamorado". El amor deja un residuo que no puede ser eliminado del todo por la muerte.

Ya desde el amor cortés se concede un valor casi milagroso al cuerpo femenino que produce en los hombres efectos casi mágicos. Se piensa que el cuerpo de la mujer es una obra perfecta de Dios que se muestra como un microcosmos, como la representación de la naturaleza en su carácter creativo y nutricio ${ }^{11}$.

Se mantiene en el Barroco la tradición del sufrimiento ante el amor no correspondido, imposible; la contraposición entre el ardor del amante y la frialdad de la amada, su despego y su desvío: "ídolo bello, a quien humilde adoro, /oye piadoso al que por ti suspira, /tus himnos canta, y tus virtudes reza" (Góngora). La 'oscura dama' shakespeariana es fuente de sufrimiento porque a pesar de conocer sus defectos no puede dejar de amarla el amante. Como nos recuerda Rougemont, toda la lírica europea tiene su origen en la poesía trovadoresca creadora del amor cortés cuyo tema es el amor, pero el amor desgraciado, imposible, el amor insatisfecho a perpetuidad que enfrenta a un amante que repite constantemente su queja y una dama que dice siempre que no. Como se ha dicho alguna vez, no pertenece a la naturaleza humana amar solo a los que nos aman sino que nos obstinamos en perseguir a los que nos huyen mientras rechazamos a los que nos solicitan. Pero a la vez, se prefiere el sufrimiento derivado del amor que la tranquilidad de la indiferencia ya que como dice la canción renacentista "penas es el traje de amadores". El sufrimiento inherente al amor prohibido se puede explicar desde el punto de vista cristiano como una especie de expiación del adulterio a través de la penitencia que supone el dolor. Cuando se sufre por el amor imposible se anhela el estado de indiferencia, pero cuando se ha logrado éste se añora el antiguo sufrimiento y el paso de uno a otro estado es tan súbito como imprevisible. Nos encontramos amando sin saber cómo, y un día nos encontramos con que el amor no existe ya. El enamoramiento es una enajenación, es una especie de trascendencia respecto de la realidad común, la apertura a un absoluto inefable que ya no es de este mundo pero que se siente más real que el propio mundo. Los amantes padecen un 'delicioso tormento' que no procede de uno ni de otros sino de una potencia externa y extraña ${ }^{12}$. El carácter radical y súbito del enamoramiento y su falta de explicación lo asemeja al hechizo, al embrujo, como algo sin por qué y que, sin embargo, se experimenta como algo inexorable, como un destino. Ya lo decía Garcilaso en su Canción cuarta: "No vine por mis pies a tantos daños:/fuerzas de mi destino me trujeron/y a la que m'atembentdenhỏentasgsitópićcos de amores imposibles está el caso del sabio que en su vejez cae enamorado, que se puede ver como un ejemplo de sumisión de la razón a la belleza y a la pasión ${ }^{13}$. El ejemplo paradigmático es el de Aristóteles y Phyllis en el que el viejo

11 Cf. Nelli R., "las recompensas del amor" en Feher M., Naddaff, R., y Tazi, N., Fragmentos para una historia del cuerpo humano. Parte segunda, Taurus, Madrid, 1991, p. 219.

12 Cf. Rougemont, D., Amor y Occidente, Ed. Kairós, Barcelona, 1979, p. 41.

13 Otro ejemplo de enamoramiento de un sabio, aunque esta vez es joven, que abandona todo por el amor de una mujer y busca al demonio en su auxilio lo tenemos en El mágico prodigioso de Calderón. La sumisión de 
filosofo cayó enamorado de la amante de su discípulo Alejandro y ésta lo utilizó como caballo montándose sobre él con una silla y dirigiéndolo con riendas. El exemplum medieval fue retomado especialmente en el renacimiento pero su influencia se extiende también al barroco ${ }^{14}$. La moraleja es una advertencia sobre los peligros del amor y el poder de las mujeres que se imponen hasta a los más sabios haciéndoles descarriar. Esta leyenda presenta una inversión curiosa de roles según la cual el sabio, varón y mayor se somete a la joven ignorante mostrando como en las cuestiones amorosas los papeles de dominante y dominado está repartidos de formas muy variadas y no siempre en la forma clásica del falocratismo según la cual el hombre es el dominante y la mujer la dominada. En este tipo de amores asimétricos, y quizás en todos, la dama es el amo y señor y el amante el siervo y el esclavo que solo puede aspirar a un desdén condescendiente que le libre del desvío y desdén frío y mudo de la copla. El desdén permanente de la amada se simboliza en esta época a través del episodio de Dafne que huyendo de Apolo se transforma en laurel, consiguiendo de esta manera, sin embargo, cierta fijeza frente a su perpetua huida anterior ${ }^{15}$. La dificultad de conseguir la atención de la dama y de superar su frialdad se ve en este soneto de Herrera que concluye así: "Porqu'el rigor de vuestro antiguo frio/no podré ya encender? Por qué no inflama/ mi estío ardiente a vuestro helado invierno?". La capacidad del más débil para imponerse al pretendidamente más fuerte en el amor se ejemplifica muy bien en la leyenda de Sinope que amada por Zeus éste le prometió para seducirla darle lo que más desease y ella, astutamente, le pidió conservarse virgen para siempre, con lo que el poderoso dios vio frustrado su deseo de poseerla. La ninfa utilizó la misma treta con todos sus pretendientes, incluido también Apolo, y vivió toda su vida en una soledad tranquila.

Este tema del amor del anciano por la jovencita se enlaza con la leyenda de Fausto, el sabio que al final de sus días siente que ha perdido su vida y añora la juventud y especialmente el amor, nunca alcanzado. Esta recaída de los ancianos en el amor quizás provenga de su deseo de no morir y de la creencia de que la relación con mujeres jóvenes les puede revitalizar. La dificultad intrínseca de esta relación imposible hace que la leyenda exija un pacto con el diablo para poderla realizar, como la propia leyenda de Fausto recoge. La asimetría de la relación se basa en que hay que cambiar cosas disímiles, a saber, placer por admiración y que hay que compensar las carencias de la edad con otras cosas como saber, poder o dinero. En resumen, que hay que conseguir capital erótico a partir de capital simbólico y eso no siempre es posible.

la pasión a los sentidos supone la pérdida del libre albedrío y la caída en manos del demonio que al cumplir su compromiso con el protagonista le entrega un espectro que se convierte en un esqueleto mostrando que la belleza que encadena a los sentidos es meramente aparente por estar sometida a la decadencia y a la muerte. Dice el protagonista Cipriano aludiendo a su enamoramiento: "Vi a Justina y, en Justina/ ocupados mis afectos, / dejé a la docta Minerva/por la enamorada Venus" y concluye dirigiéndose al Dios cristiano, único valor de verdad y único valor verdadero: “...porque a saber llego /que sin el gran dios que busco,/que adoro y que reverencio,/las humanas glorias son/ polvo, humo, ceniza y viento". En el mismo sentido dice Quevedo: “A fugitivas sombras doy abrazos;/ en los sueños se cansa el alma mía;/ pero luchando a solas noche y día/ con un trasgo que traigo entre mis brazos." La figura de la amada es una sombra fugitiva, un sueño, un espectro producto de la imaginación del amante.(Cf. Parker A., op.cit, pp. 177 y 188). Esta idea de que detrás de la belleza está la muerte se representa a veces mediante la figura de una bella joven cuya espalda, abierta, muestra las vísceras y el esqueleto.

14 Cf. Braun L., Iconographie et Philosophie, Presses Universitaires de Strasbourg, Strasbourg, 1994, pp. $387-396$.

15 Cf. Bocángel G., La lira de las musas, Cátedra, Madrid, 1985, pp. 60 y 13. 
En la filosofía del amor barroca encontramos influencias del neoplatonismo y del neoestoicismo con su idealismo que lleva a menospreciar el amor humano en detrimento del amor divino y una concepción que piensa que es posible el control racional total de las pasiones, pero a la vez en dicha concepción amorosa late la sospecha de que a pesar de todo el amor carnal sigue siendo un valor, y sobre todo una duda bastante fundada de que no es posible controlar completamente las pasiones con la razón sino que a lo más que podemos aspirar es a hacer jugar unas pasiones con otras sopesándolas entre sí.

El ideal del amor cortés tardomedieval se conecta con el amor ideal del neoplatonismo porque los dos, frente al amor caballeresco que sí pretende una culminación posible aunque sea retardada, son imposibles, mero anhelo sin consumación posible, y los dos exigen la neutralización del deseo sensual, figurado a menudo por la figura del Hombre Salvaje y peludo ${ }^{16}$. El amor platónico es un amor no sensual ,basado en la mente, que se dirige a la belleza espiritual y en último término a Dios. El neoplatonismo de corte garcilasista pasa del sufrimiento por el conflicto entre sensualidad y razón a una especie de serenidad resignada que supone la aceptación de la tristeza derivada del carácter perecedero de toda belleza y amor humanos ${ }^{17}$, con lo que al final concuerda con la devaluación de lo terrenal promovido por la religión. El neoplatonismo que se trasluce en la obra de Castiglione y de Bembo coincide con el neoestoicismo en pensar que es posible supera la idea de amor como sufrimiento y la sumisión a la pasión si uno se centra en la belleza espiritual y moral del amado $^{18}$.También en esta época se da mucha importancia a la representación realista de la sensualidad que supone la autonomía de lo sensible. En el 'Amor vencedor' de Caravaggio se escenifica el triunfo del amor sobre las artes y las ciencias.

\section{Conclusión}

El Barroco como época ambigua ${ }^{19}$ por excelencia muestra una gran presencia del cuerpo a pesar de los intentos de reducirlo mediante su negación y sublimación. En esta época, la carne existe y se despliega en el amor; la carne, en tanto que vida, resiste en la revuelta al poder absoluto; la carne puede trascenderse a sí misma en el ascetismo religioso pero también pude sublimarse en la literatura y el arte. Esta época turbulenta muestra la existencia humana no como una armonía equilibrada, como era el ideal renacentista, sino como una tensión angustiosa entre afirmación de la vida y apoteosis de la muerte, entre el poder omnímodo y la resistencia difusa, entre la sublimación del amor imposible y la consumación del amor carnal con los desastres y estragos que esto acarrea. La carne se nos muestra pues, como algo que martirizar en búsqueda de la salvación, como algo que domeñar mediante el suplicio, pero también como algo que acariciar en el amor profano y algo que contemplar y adorar en el amor ideal.

16 Cf. Parker A., La filosofia del amor en la literatura española: 1480-1680, Cátedra. Madrid, 1986, p. 39.

17 Cf. Parker A., op.cit., p. 64.

18 Cf.Parker A., op. cit., p. 128.

19 He tratado la ambigüedad barroca en mi libro Próspero en el laberinto. Las dos caras del Barroco, Dikynson, Madrid, 2014, especialmente en la Introducción: Ambigüedades barrocas, pp. 15-23. 


\section{Bibliografía}

Feher Michel, Naddaff Ramona, y Tazi Nadia, (1991-1992), Fragmentos para una historia del cuerpo humano. (3 volúmenes) Taurus, Madrid.

Foucault, Michel, (1975), Surveiller et punir. Naissance de la prison, Gallimard, París.

Martínez, Francisco José (2014), Próspero en el laberinto. Las dos caras del Barroco, Dikynson, Madrid.

Panofsky Erwin, (1992), La sculture funéraire. De l'ancienne Egypte à Bernini, Flammarion, París.

Parker Alexander, (1986), La filosofía del amor en la literatura española: 1480-1680, Cátedra. Madrid.

Rougemont, Denis, (1979), Amor y Occidente, Ed. Kairós, Barcelona. 